\title{
Ethanol formed from arabinose: a rapid method for detecting Escherichia coli
}

\author{
P. J. COLOE
}

From the Department of Microbiology, Monash University Medical School, Prahran, Victoria, Australia 3181

SUMMARY Head-space gas-liquid chromatography showed that Escherichia coli are consistent in their ability to ferment arabinose with the production of ethanol. In both still and shaken cultures ethanol production is closely aligned with growth. Also ethanol production is related to inoculum size so that varying sizes of inocula may be distinguished by choosing a time of sampling early in growth. The method is suitable as a rapid test for $E$. coli and is applicable for use in detecting $E$. coli urinary tract infections.

Within the last five years many new methods have been introduced into microbiology for the rapid detection of bacteria. Techniques such as limulus lysate procedures (Jorgensen and Jones, 1975; Ross et al., 1975), radiometric procedures (Buddemeyer, 1976), and microcalorimetery (Beezer et al., 1974, 1975) have all been tried. However, these methods, while rapid, are relatively non-specific. Henceforth they are unsuited to rapid detection of bacteria when normal bacterial flora may be present that are similar or identical to the organisms causing the infection. In the case of urinary tract infections the method must also be able to quantify the number of organisms present so as to conform to Kass's (1957) criterion. Clearly these methods will not do that.

A method that shows promise for rapid detection and quantification, and which could be applied to urinary tract infections, is the prototype system for rapid detection and quantification of Escherichia coli and Proteus spp in urine described by Hayward et al. (1977a). They did extensive work on the metabolism of methionine by Proteus spp and concluded that the methyl mercaptan and dimethyl disulphide formed from methionine by Proteus spp in liquid culture could be used for the rapid detection of Proteus spp.

On a minor scale Hayward et al. (1977b) also studied fermentation of lactose and arabinose by some strains of enterobacteria. They found ethanol production from lactose in still cultures seemed to be a consistent property of $E$. coli but a variable property of other enterobacteria, whereas, in the 19 strains they tested, ethanol production from

Received for publication 12 October 1977 arabinose in still culture was a consistent property. In an attempt to develop a rapid test specific for $E$. coli they established a test based on ethanol produced from lactose.

Unfortunately, ethanol produced from lactose is not specific for $E$. coli. Klebsiella aerogenes, for example, are equally as active. In view of this, ethanol formed from arabinose may be more useful as a rapid test for $E$. coli provided it is recognised that occasionally some other closely related enterobacteria may mimic $E$. coli. If distinction between these bacteria is required tests within the confines of the method and utilising the ability to ferment could be developed.

This paper reports a rapid method using gasliquid chromatography for identifying and quantifying $E$. coli by detecting the ethanol produced from arabinose. The method is suitable for the rapid detection of $E$. coli and could be used to detect $E$. coli in urine. Also it could be combined with the method for rapid detection of Proteus spp developed by Hayward et al. (1977b) to give a rapid method for detecting E. coli and Proteus spp in urine.

\section{Material and methods}

Forty-nine strains of $E$. coli were studied, 39 of which were obtained from clinical material including urine (29), faeces (8), pus (1), and sputum (1). A further 10 strains were obtained from culture collections including Alfred Hospital Melbourne (6), National Collection of Type Cultures, London, Nos. NCTC 8196 and NCTC 8450 (2), and Monash University Culture Collection (2). One of the strains of 
E. coli (H19), isolated from urine, was also used for particular growth experiments. All organisms were identified by the method of Cowan and Steel (1965).

Ethanol (Townson and Mercer, Melbourne, Australia) redistilled to constant boiling point was used as a gas chromatographic standard. Whenever available biochemical-grade chemicals (British Drug Houses) were used for preparing a defined medium (Hayward et al., 1977a) to which arabinose was added to replace potassium lactate. The medium was adjusted to $\mathrm{pH} \mathbf{7 \cdot 4}$ and sterilised by filtration through sintered glass. Undefined medium, culture conditions, and measurements of growth were described by Coloe and Hayward (1976).

Ethanol was detected by gas-liquid chromatography using a Perkin-Elmer 881 gas chromatograph equipped with a flame ionisation detector and a Leeds and Northrup Speedomax W chart recorder. The stainless steel column $(3.66 \mathrm{~m}(12 \mathrm{ft}) \times 3.175 \mathrm{~mm}$ $(0.125$ in) outside diameter) was packed with $5 \%$ Carbowax 20 M on Chromosorb G, acid washed, DMCS treated 60/80 mesh, and the carrier gas was nitrogen at a flow rate of $21 \mathrm{ml} / \mathrm{min}$. Temperatures used were column oven $100^{\circ} \mathrm{C}$, detector $120^{\circ} \mathrm{C}$, and injector $130^{\circ} \mathrm{C}$.

Ethanol from bacterial cultures was identified initially by comparing the retention times of peaks with the peaks obtained after head-space analysis of standard $0.05 \mathrm{~m}$ ethanol solution. The identity of the product was confirmed as ethanol by mass-spectrometry.

Six millilitres of culture fluid or standard solution were added to $6 \mathrm{~g}$ of anhydrous $\mathrm{K}_{2} \mathrm{CO}_{3}$ in a $14 \mathrm{ml}$ serum vial sealed with a rubber cap. The mixture was shaken on a rotary shaker at $160 \mathrm{rpm}$ in air at $37^{\circ} \mathrm{C}$ for five minutes and then heated at $60^{\circ} \mathrm{C}$ in a water bath for five minutes, after which $500 \mu$ l head-space gas was removed with a gas-tight syringe and injected into the gas chromatograph.

\section{Results}

\section{ETHANOL PRODUCTION FROM ARABINOSE BY}

E. COLI

$E$. coli $\mathrm{H} 19$ was incubated unshaken for 24 hours in defined medium supplemented with $0.066 \mathrm{M}(1 \%$ $\mathrm{w} / \mathrm{v}$ ) arabinose. Analysis of the headspace gas of the culture fluid showed a peak that corresponded to ethanol. Ethanol was not detected in a control culture of $E$. coli in defined medium without arabinose.

\section{RELATIONSHIP BETWEEN ETHANOL}

PRODUCTION AND AERATION OF CULTURE

Since aeration increases the rate of growth of $E$. coli its influence on the rate of ethanol production was investigated. Defined medium supplemented with

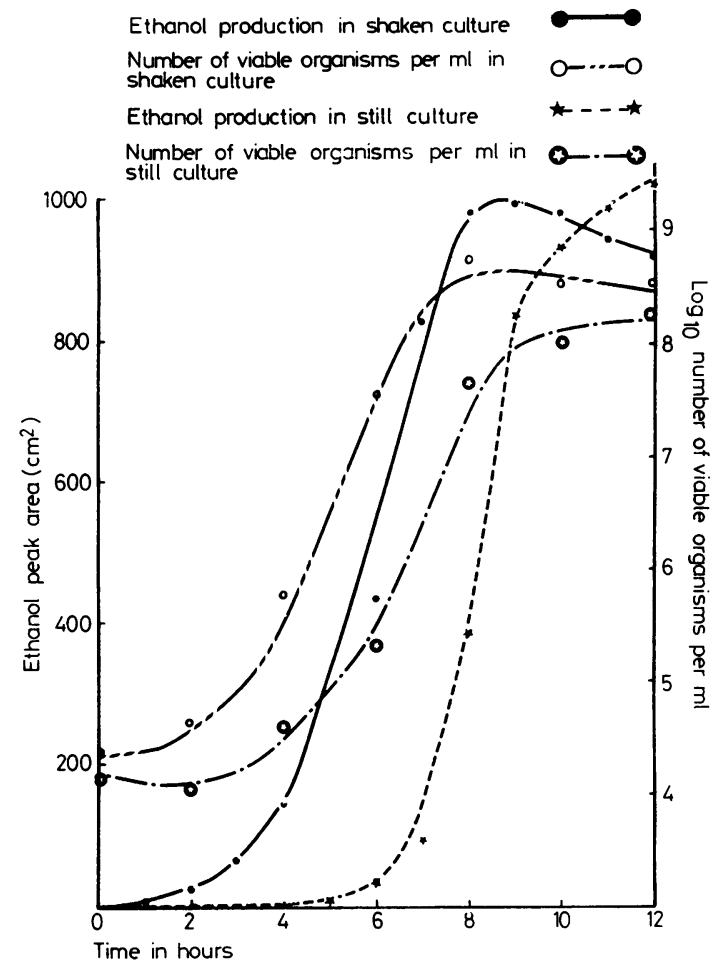

Fig. 1 Time course of ethanol production by E. coli from shaken and still cultures in arabinose-supplemented defined medium.

$0.05 \mathrm{M}$ arabinose was inoculated with approximately $10^{4} \mathrm{E}$. coli $\mathrm{H} 19 / \mathrm{ml}$, incubated either still or shaken, and sampled two-hourly up to 12 hours in order to perform viable counts and to determine ethanol production (Fig. 1). Ethanol was detected in the still culture early in the logarithmic phase when the viable count was low and continued to increase after the viable count had become stationary. There was a shorter lag phase in the shaken culture. In this ethanol was detected early in the logarithmic phase, starting at two hours, reaching after six hours more than $50 \%$ of the highest concentration recorded (at eight hours), and falling by about $10 \%$ by 12 hours.

RELATIONSHIP BETWEEN ETHANOL

PRODUCTION AND ARABINOSE

CONCENTRATION

Inocula to give $10^{5} \mathrm{E}$. coli $\mathrm{H} 19 / \mathrm{ml}$ were grown unshaken for 18 hours in defined medium supplemented with concentrations of arabinose ranging from $0.001 \mathrm{M}$ to $0.1 \mathrm{M}$. The amount of ethanol produced increased with greater arabinose concentrations up to $0.05 \mathrm{M}$ but higher concentrations did not lead to a much higher yield of ethanol (Table 1). 
Table 1 Relationship between arabinose concentration and yield of ethanol

\begin{tabular}{lc}
\hline $\begin{array}{l}\text { Arabinose concentration } \\
\text { (M) }\end{array}$ & $\begin{array}{c}\text { Ethanol yield } \\
\left.\text { (peak area in } \mathrm{cm}^{2}\right)\end{array}$ \\
\hline 0.001 & 0 \\
0.010 & 300 \\
0.025 & 850 \\
0.050 & 1000 \\
0.075 & 1050 \\
0.100 & 1100 \\
\hline
\end{tabular}

ETHANOL PRODUCTION FROM ARABINOSE IN UNSHAKEN CULTURES OF 49 STRAINS OF

E. COLI

Cultures of $E$. coli inoculated to give $10^{6}$ organisms/ $\mathrm{ml}$ in $\mathbf{0 . 0 5} \mathrm{M}$ arabinose-supplemented defined medium and in unsupplemented defined medium as controls were incubated without shaking for eight hours, when the culture was near the middle of the logarithmic phase of growth and the different rates of growth and ethanol production between cultures were greatest. The extinction and yield of ethanol from cultures was determined (Table 2). All 49 strains yielded ethanol from the arabinose-supplemented medium. The amount of ethanol fell within a range that was less than twofold although extinction covered a wider range. Ethanol was not detected in cultures of any of the 49 strains grown in unsupplemented defined medium.

\section{RELATIONSHIP BETWEEN INOCULUM SIZE}

AND AMOUNT OF ETHANOL PRODUCED

Arabinose-supplemented defined medium was inoculated with $8.0 \times 10^{5}, 4.0 \times 10^{6}$, and $2.4 \times 10^{7}$ E. coli strain $\mathrm{H} 19 / \mathrm{ml}$. The cultures were incubated without shaking. Samples were taken at two and four hours and then hourly up to 10 hours in order to make viable counts and to measure ethanol production (Fig. 2). Ethanol was detected in the culture with the largest inoculum after only two hours and had reached more than half its final yield in four hours. Only a very small amount of ethanol was detected in the cultures with inocula of $4.0 \times 10^{6}$ or $8.5 \times 10^{5}$ at two hours, and the yields at four hours were small when compared with the culture with the largest inoculum. The amounts of ethanol formed after four hours by the cultures with a high inoculum were

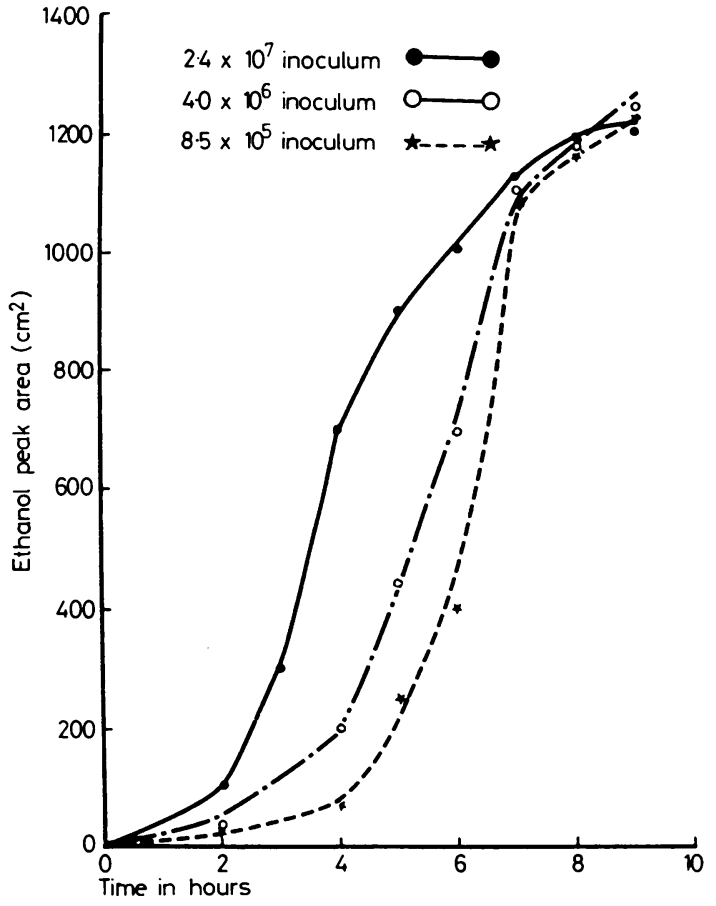

Fig. 2 Time course of ethanol production from arabinosesupplemented defined medium by various inocula of E. coli.

clearly distinguishable from those produced by cultures with a low inoculum. At 10 hours all cultures yielded about the same amount of ethanol.

\section{RELATIONSHIP BETWEEN MEDIUM AND} ETHANOL PRODUCTION

Yeast-extract peptone water supplemented with arabinose and arabinose-supplemented defined medium were inoculated with about $10^{6}$ E. coli $\mathrm{H} 19$ / $\mathrm{ml}$, incubated with shaking, and sampled at twohourly intervals for eight hours to determine extinction and measure ethanol production. In both media significant amounts of ethanol were detected in four hours and reached a maximum by six hours.

Table 2 Range of yields of ethanol and extinction $(500 \mathrm{~nm})$ from eight-hour unshaken cultures of 49 strains of E. coli in defined medium alone or enriched with arabinose

\begin{tabular}{|c|c|c|c|c|}
\hline \multirow[t]{2}{*}{ Arabinose enrichment } & \multicolumn{2}{|c|}{ Ethanol production (peak area in $\mathrm{cm}^{2}$ ) } & \multicolumn{2}{|c|}{ Extinction $(500 \mathrm{~nm})$} \\
\hline & Mean $( \pm S D)$ & Range & $\operatorname{Mean}( \pm S D)$ & Range \\
\hline $\begin{array}{l}\text { Present } \\
\text { Absent }\end{array}$ & $\underset{0}{1008} \pm 155$ & $\begin{array}{l}750-1296 \\
0\end{array}$ & $\begin{array}{l}0.71 \pm 0.09 \\
0.07 \pm 0.05\end{array}$ & $\begin{array}{l}0.35-0 \cdot 85 \\
0.03-0.08\end{array}$ \\
\hline
\end{tabular}




\section{Discussion}

The results show that detection of ethanol produced from arabinose is a suitable method for rapid detection of $E$. coli. An inoculum of $10^{6} E$. coli was recognised in six hours in still culture and in less than four hours when shaken. In both still and shaken cultures ethanol production was closely aligned to growth, starting when the viable count was low and increasing throughout the logarithmic phase. In the still cultures ethanol concentration continued to rise after the onset of the stationary phase, when $20 \%$ of the total yield detected was formed. However, in the shaken culture ethanol concentration decreased after the onset of the stationary phase, indicating that the ethanol was destroyed faster than it was formed during the stationary phase in shaken culture. It was the reverse in still culture. Ethanol production from arabinose seems to be a consistent property of $E$. coli since all of the 49 strains of $E$. coli produced large amounts of ethanol after eight hours in arabinosesupplemented medium.

Because the inoculum size and the onset of production of ethanol are related varying sizes of inoculum may be distinguished by choosing a time early in growth (Fig. 2). The technique is thus well suited as a rapid test for $E$. coli in urine since it can distinguish concentrations of greater or less than $10^{5}$ $E$. coli $/ \mathrm{ml}$. It is much quicker than conventional laboratory methods, easy to carry out, and relatively cheap per sample apart from the initial cost of the gas chromatograph. The method may also be combined with the rapid method for detecting Proteus spp (Hayward et al., 1977b) to give a rapid method for detecting $E$. coli and Proteus spp in urine (Coloe, 1977).

I thank Dr Nancy Hayward and Professor S. Faine for their encouragement and advice and Dr A. J. C. Nicholson, Division of Chemical Physics, Commonwealth Scientific and Industrial Research Organisation, for identifying ethanol by mass spectrometry.
References

Beezer, A. E., Bettelheim, K. A., and Al Salihi, S. (1975). Microcalorimetric assessment of bacterial growth and activity (Abstract). Proceedings of the Society for General Microbiology, 3, 15.

Beezer, A. E., Bettelheim, K. A., Newell, R. D., and Stevens, J. (1974). The diagnosis of bacteriuria by flow microcalorimetry - a preliminary investigation. Science Tools, 21, 13-14, 16.

Buddemeyer, E. U. (1976). Automatic quantitative radiometric measurement of bacterial growth. In: Proceedings of the 2nd International Symposium on Rapid Methods and Automation in Microbiology, edited by H. H. Johnston and S. W. B. Newsom, p. 4. Learned Information (Europe) Ltd., Oxford, England.

Coloe, P. J., and Hayward, N. J. (1976). The importance of prolonged incubation for the synthesis of dimethylnitrosamine by enterobacteria. Journal of Medical Microbiology, 9, 211-223.

Cowan, S. T., and Steel, K. J. (1965). Manual for the Identification of Medical Bacteria. Cambridge University Press, Cambridge.

Hayward, N. J., Jeavons, T. H., Nicholson, A. J. C., and Thornton, A. G. (1977a). Development of specific tests for the rapid detection of Escherichia coli and all species of Proteus in urine. Journal of Clinical Microbiology, 6, 195-201.

Hayward, N. J., Jeavons, T. H., Nicholson, A. J. C., and Thornton, A. G. (1977b). Methyl mercaptan and dimethyl disulphide production from methionine by Proteus species detected by head-space gas-liquid chromatography. Journal of Clinical Microbiology, 6, 187-194.

Jorgensen, J. H., and Jones, P. M. (1975). Comparative evaluation of the limulus assay and the direct gram stain for detection of significant bacteriuria. American Journal of Clinical Pathology, 63, 142-148.

Kass, E. H. (1956). Asymptomatic infections of the urinary tract. Transactions of the Association of American Physicians, 69, 56-64.

Ross, S., Rodriguez, W., Controni, G., Korengold, G., Watson, S., and Khan, W. (1975). Limulus lysate test for gram-negative bacterial meningitis. Journal of the American Medical Association, 233, 1366-1369. 